\title{
Prospective observational study to assess the somatic growth in very low birth weight infants
}

\author{
Dalwinder Janjua ${ }^{1}$, Japna Singh ${ }^{2}$, Amit Agrawal' ${ }^{3}$, Devendrasing Vijaysing Jadhav ${ }^{\mathbf{1}}$ \\ From ${ }^{1}$ Neonatologist, Department of Neonatology, Al Jalila Children's Hospital, ${ }^{2}$ Radiologist, Department of Radio-diagnosis, International Modern \\ Hospital, Dubai, United Arab Emirates, ${ }^{3}$ Associate Professor, Department of Pediatrics, Gandhi Medical College, Bhopal, Madhya Pradesh, India
}

\begin{abstract}
Background: The birth weight is the first weight measured; an infant with low birth weight (LBW) is more likely to have poor somatic growth during childhood and develop markers of metabolic risk factors at his/her later age. Objectives: The objective of the study is to evaluate the somatic growth of very LBW (VLBW) infants at discharge and 40 weeks postmenstrual age and to compare the growth of small for gestational age (SGA) and appropriate for gestational age (AGA) babies. Materials and Methods: This prospective observational study was conducted over a period of 1 year at the neonatal unit and high-risk follow-up clinic of a tertiary care hospital in north India. VLBW babies (weight $<1500 \mathrm{~g}$ ), admitted within $72 \mathrm{~h}$ of life and discharged alive, were followed up prospectively. The baseline data were collected before discharge from the hospital and babies were followed up till the 40 weeks post-menstrual age. Results: Of 53 babies enrolled, one baby had a congenital malformation, six died during neonatal intensive care unit stay, and four were not followed up. Finally, 42 babies were followed for 40 weeks. The mean gestational age was $30 \pm 2.5$ weeks and mean birth weight was $1199 \pm 216 \mathrm{~g}$. The mean $\mathrm{Z}$ scores for weight, length and head circumference at birth were $-0.88,-0.59$, and -0.64 , respectively. These changed to $-1.12,-1.12$, and -1.11 , respectively, at the time of discharge and $-1.69,-1.03$, and -0.73 , respectively at post-menstrual age of 40 weeks. During NICU stay, both SGA and AGA revealed a growth lag as shown by a drop in Z scores for all parameters. Exclusive enteral feeding is feasible for VLBW infants without any difference in growth compared to babies given short-term parenteral nutrition. Despite aggressive enteral feeding, only one baby had necrotizing enterocolitis and none of the babies developed late-onset sepsis. Conclusions: In our study, both SGA and AGA infants exhibited a growth lag during the hospital stay as indicated by a fall in $\mathrm{Z}$ scores for all three parameters from birth to discharge. Exclusive enteral feeding is feasible for VLBW infants without any difference in growth compared to babies given short-term parenteral nutrition. Furthermore, rapid progression of feeds did not have any significant adverse effects in our study population.
\end{abstract}

Key words: Head circumference, Length, Postnatal growth, Very low birth weight infants, Weight, Z score

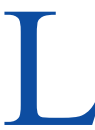

ow birth weight (LBW) may lead to serious health problems in adult life and is a cause of concern in many countries, India being one of them [1]. Birth weight is an important predictor of an infant's growth and survival and is predominantly determined by the mother's health and nutritional status before conception as well as during pregnancy. LBW (birth weight $<2500 \mathrm{~g}$ ) results in impaired growth, a higher risk of mortality and morbidity, impaired brain development, and risk of chronic diseases in later life. LBW infants are at risk for impaired growth during intrauterine life as well as the ex-utero environment with poor nutrition. In recent years, many advances in prenatal care have increased the understanding of neonatal physiology, as well as the survival rate of LBW and premature infants [2].

\section{Access this article online}

Received - 01 January 2022

Initial Review - 05 January 2022

Accepted - 08 January 2022

DOI: $10.32677 /$ ijch.v9i1.3225
A large Indian study on long-term follow-up of LBW babies reported that LBW babies were significantly disabled than the normal controls [3]. Still, there is a paucity of literature on the growth outcome of very LBW (VLBW) infants from developing countries including India. Therefore, there is a need for follow-up studies from developing countries to assess the long-term outcome of VLBW babies. In the present study, we followed a cohort of VLBW neonates to evaluate their somatic growth at discharge and 40 weeks postmenstrual age as well as to compare the growth of small for gestational age (SGA) and appropriate for gestational age (AGA) babies. This may also serve as a comparison to the standard of care provided to babies in the neonatal intensive care units (NICUs) and may be used as a guide for further improvement in neonatal care.

Correspondence to: Dr. Dalwinder Janjua, Department of Neonatology, A1 Jalila Children's Hospital, Dubai, United Arab Emirates. E-mail: dalwinderjanjua@ gmail.com

(C) 2022 Creative Commons Attribution-NonCommercial 4.0 International License (CC BY-NC-ND 4.0). 


\section{MATERIALS AND METHODS}

This prospective observational study was conducted over a period of 1 year at the Neonatal Unit and high-risk follow-up clinic of a tertiary care teaching hospital. VLBW babies (weight $<1500 \mathrm{~g}$ ), admitted within $72 \mathrm{~h}$ of life and discharged alive, were followed up prospectively. The baseline data were collected before discharge from the hospital and babies were followed up till 40 weeks postmenstrual age. Babies with major congenital malformations (major cardiac malformation, anencephaly, obstructive uropathy, congenital diaphragmatic hernia, and intestinal atresia) and syndromic babies were excluded from our study. Infants were classified SGA if the birth weight was below $10^{\text {th }}$ centile as per Fenton's growth charts $[4,5]$.

The weight, length, and head circumference (HC) were recorded at birth, discharge, and at 40 weeks post-menstrual age. Weight was taken on a standard electronic weighing scale with an error of $\pm 5 \mathrm{~g}$ without clothes. The length was measured with an infantometer. The infant was held supine and legs fully extended. The feet were pressed against the movable foot piece with the ankles flexed to $90^{\circ}$. HC was measured with non-stretchable fiberglass tape at the occipitofrontal diameter. The maximum weight loss was calculated from the difference of minimum weight and birth/admission weight. The age at maximum weight loss and times taken to regain birth weight were also calculated.

\section{Follow-Up}

To ensure a good follow-up rate, the permanent and present addresses along with phone numbers were recorded. For cases that did not turn up for the follow-up, parents were contacted by the principal investigator. For babies who failed to have follow-up till 40 weeks post-menstrual age, anthropometric data available till discharge/last visit was considered.

\section{Feeding Protocol}

For babies $<600 \mathrm{~g}, 1 \mathrm{ml}$ feed (only expressed breast milk) every $6 \mathrm{~h}$ was started at $24 \mathrm{~h}$ of age if the baby remained hemodynamically stable with a volume increase of $1 \mathrm{ml} /$ day after every $48 \mathrm{~h}$. For babies between 600 and $999 \mathrm{~g}$, feed of $1 \mathrm{ml}$ every $4 \mathrm{~h}$ was started at $24 \mathrm{~h}$ of age with a volume increase of $1 \mathrm{ml} /$ day after every $48 \mathrm{~h}$. In babies with birth weights between 1000 and $1399 \mathrm{~g}$, feed of $2 \mathrm{ml}$ every $4 \mathrm{~h}$ was started at $12 \mathrm{~h}$ of age with a volume increase of $3 \mathrm{ml} /$ day after every $36 \mathrm{~h}$. For babies, more than $1400 \mathrm{~g}$, feed of $2 \mathrm{ml}$ every $2 \mathrm{~h}$ was started at $12 \mathrm{~h}$ of age with a volume increase of $4 \mathrm{ml} /$ day after every $24 \mathrm{~h}$. Target feeds were $200 \mathrm{ml} / \mathrm{kg} /$ day. IV fluids were stopped once the baby reached $100 \mathrm{ml} / \mathrm{kg} /$ day of enteral feed. Spoon feeds were tried once the baby reached 33 weeks of postmenstrual age or earlier if the baby demanded so. Minimal enteral nutrition (MEN) was started if the baby remained hemodynamically stable (not on any inotropes) and had no increasing oxygen requirement till the time designated for initiation. As far as possible only breast milk was used for MEN.

Feed progression was made if the baby tolerated MEN well, remained hemodynamically stable; there was no significant increase in abdominal girth and no bilious or bloody aspirates (aspiration done only if there was significant abdominal distension; $\geq 1.5 \mathrm{~cm}$ for babies below $1000 \mathrm{~g}$ and $\geq 2.0 \mathrm{~cm}$ for babies more than $1000 \mathrm{~g}$ ) If there were bilious or bloody aspirates or more than $50 \%$ of the previous feeds as aspirate, feeds were withheld for the next feed only but if it occurred on the next feed also, feeds were withheld for $24 \mathrm{~h}$ and the baby was re-evaluated after $24 \mathrm{~h}$ for readiness to accept feeds. In case of bloody aspirate, if fresh blood was aspirated, feeds were withheld for $24 \mathrm{~h}$. If necrotizing enterocolitis was suspected in a neonate, feeds were withheld for a minimum of $72 \mathrm{~h}$ before initiating feeds. At discharge, mothers were advised to continue breastfeeding or formula (preterm formula), if the baby was already receiving formula feeds in the NICU.

\section{Statistical Analysis}

The $\mathrm{Z}$ scores for weight, length, and $\mathrm{HC}$ for each gestation were calculated based on means and standard deviations at birth, at discharge and at 40 weeks post-menstrual age. Mean $\mathrm{Z}$ scores for weight, length, and $\mathrm{HC}$ of the whole cohort were compared at birth, discharge, and 40 weeks and similar comparisons were made between SGA and AGA infants.

\section{RESULTS}

During the study period, around 53 infants were admitted to our hospital and around 42 were taken for consideration in this study (Fig. 1). Of these 42 babies, 37 (70\%) were male. The mean gestational age was $30 \pm 2.5$ weeks and the mean birth weight was $1199 \pm 216$ g. Demographic profile of the study population has been presented in Table 1. At 40 weeks post-menstrual age, $21 \%$ of VLBW infants were underweight. We did not find any association between the infant diet and growth failure. The mean time to reach full enteral feeds $(200 \mathrm{ml} / \mathrm{kg} / \mathrm{d})$ was $7.11 \pm 2.12$.

The mean $\mathrm{Z}$ scores for weight, length and $\mathrm{HC}$ at birth were $-0.88,-0.59$, and -0.64 , respectively. At the time of discharge, the same were $-1.12,-1.12$, and -1.11 , respectively, and -1.69 , -1.03 , and -0.73 , respectively, at 40 weeks of post-menstrual age (Table 2).

As evident from Fig. 2, babies weighing less continued to grow poorly but as their weight increased, they tended to grow better. The relationship between gestation at birth and change in weight is shown in Fig. 3.

\section{DISCUSSION}

The main objective of this study was to evaluate the evolution of anthropometric parameters and the nutritional status of VLBW infants and to analyze factors influencing growth failure. At 40 weeks post-menstrual age, $21 \%$ of LBW infants were underweight. We did not find any association between the LBW infant diet and growth failure. Up to 60 million infants are born at home annually [6], and up to $48 \%$ of infants worldwide are not weighed at birth [7]. The prevalence of VLBW neonates 
$(70 \%)$ in our study is comparable to the previous reports $[6,7]$. In a follow-up study done by Mukhopadhyay et al. [8], a similar trend of growth failure was found till the corrected gestational age (CGA) of 1 year. In their study, mean $\mathrm{Z}$ scores for weight $(-2.3 \pm 1.2--1.7 \pm 1.4 ; \mathrm{p}=0.005)$ and length $(-2.1 \pm 1.5--1.5 \pm$ 1.3; $\mathrm{p}=0.004$ ) increased significantly, from 40 weeks to 1 year of age. At 40 weeks, $63 \%, 53 \%, 13 \%$, and $52 \%$ of neonates were underweight, stunted, had microcephaly and wasting, respectively which changed to $41 \%, 32 \%, 21 \%$, and $27 \%$, respectively, at 1 year of age. They concluded that weight Z-score at 3 months of age was an independent predictor of malnutrition at 1 year.

In Senegal, Faye et al. [9] reported extra-uterine growth retardation $(86 \%)$, underweight in $61 \%$, and $41 \%$ babies at 3 months, and 6 months of CGA, respectively. Recently, there are other opinions about the adjustment of postnatal growth trajectories because all neonates including very preterm infants lose extracellular fluid after birth and tend to follow a lower percentile than their birth percentile. However, extrauterine growth restriction commonly occurs in neonatal units $[10,11]$. The growth of VLBW infants during the first 12 months of life is

Table 1: Baseline characteristics of the study population

\begin{tabular}{lc}
\hline Characteristic & $\begin{array}{c}\text { Number (percentage) } \\
\text { /mean } \pm \text { SD }\end{array}$ \\
\hline Male & $37(70)$ \\
Mean birth weight (g)* & $1199 \pm 215.7$ \\
Extremely Low Birth Weight & $10(21)$ \\
Mean Gestation* & $30 \pm 2.5$ \\
Small for Gestational Age & $10(21.7)$ \\
Appropriate for Gestational Age & $36(78.3)$ \\
Inborn & $33(62)$ \\
Antenatal Steroid & \\
Complete & $17(37)$ \\
Partial & $11(24)$ \\
Multiple pregnancies & 10 \\
Abnormal Doppler & $10(19)$ \\
Mean duration of initial IV fluid (Hr) & $78.77 \pm 32.43$ \\
Cumulative weight loss (\%) & $12.06 \pm 5.00$ \\
Days to reach full feeds & $7.11 \pm 2.12$ \\
No of days to regain birth weight & $11.73 \pm 3.72$ \\
Mean gestation at discharge & 36 \\
The median duration of hospital stay & $30(14-45)$ \\
Late-onset sepsis & 0 \\
Necrotising enterocolitis & $1(2.1)$ \\
Patent ductus arteriosus & $11(23.9)$ \\
Chronic lung disease & $5(10.6)$ \\
\hline &
\end{tabular}

influenced by several factors, from the nutritional status in utero, nutritional practices in the NICU and the follow-up period, as well as regional, cultural, and environmental aspects, which need to be clarified in further studies designed for this purpose [12].

Another study by Chand et al. [13] studied the early morbidities of LBW neonates, and found a significant association of birth weight with hypothermia and hypocalcemia, whereas gestational age was associated with hypocalcemia and respiratory distress syndrome. They also concluded that the priority should be given to adequate attention to LBW neonates. As advances in neonatal care have significantly improved the survival rate of VLBW preterm infants, continuous growth monitoring from the time of birth is a good predictor of clinical status, outcomes of treatment, and nutritional status. In particular, since growth has a direct effect on neurological development, monitoring of growth patterns is very important for NICU clinicians [14].

SGA is defined as a birth weight of $<10^{\text {th }}$ percentile for the gestational age [15]. The lack of data available has encouraged the development of a mathematical model to calculate the expected number of adverse events, including neonatal and maternal deaths, SGA, preterm birth, and major congenital malformations [16]. According to the Fenton's intrauterine growth references, infants in our study were smaller at birth in all three parameters. These infants exhibited a growth lag during the hospital stay as indicated by a fall in $\mathrm{Z}$ score in each of the three parameters from birth to discharge. Both SGA and AGA infants exhibited a decrease of approximately $0.8 \mathrm{Z}$ score in all parameters. The observation is similar to a study done by Saluja et al. [17]. In their study also, both SGA and AGA infants had a significant drop of approximately $1 \mathrm{Z}$ score in all parameters including weight, height, and $\mathrm{HC}$ during hospital stay.

A greater incidence of poor growth has been reported in SGA infants than in AGA infants. Sung et al. [18], compared SGA infants with AGA infants matched for either gestational weight or birth weight up to the age of 3 years and concluded that intrauterine growth restriction in VLBW infants has a significant long-term impact on growth. In our study, SGA infants had a significant drop in their growth $\mathrm{Z}$ scores during the hospital stay but showed adequate growth of length and $\mathrm{HC}$ at 40 weeks post-menstrual age. SGA and AGA babies continued to remain within 1 standard deviation in all the parameters at discharge and 40 weeks postmenstrual age. The mean time to reach full enteral feeds $(200 \mathrm{ml} /$ $\mathrm{kg} / \mathrm{d}$ ) was $7.11 \pm 2.12$. In a study done by Jaiswal et al. [19], the mean age at full feeds $(150 \mathrm{ml} / \mathrm{kg} / \mathrm{d})$ was $7.2 \pm 4.7$ days. It was delayed by nearly 1 week ( 13.5 days) in the study by Gianini et al. [20] and by 1-2 weeks (median of 15 and 20 days in the conventional and aggressive nutritional groups, respectively).

Table 2: Growth parameters at birth, discharge, and 40 weeks post-menstrual age

\begin{tabular}{|c|c|c|c|c|c|c|c|c|c|}
\hline \multirow[t]{2}{*}{ Z Score } & \multicolumn{3}{|c|}{ At birth } & \multicolumn{3}{|c|}{ At discharge } & \multicolumn{3}{|c|}{ At 40 weeks PMA } \\
\hline & ALL & AGA & SGA & ALL & AGA & SGA & ALL & AGA & SGA \\
\hline Weight & -0.88 & -0.48 & -2.24 & -1.12 & -0.71 & -2.58 & -1.69 & -1.31 & -3.07 \\
\hline Length & -0.59 & -0.21 & -1.96 & -1.12 & -0.63 & -2.90 & -1.03 & -0.57 & -2.73 \\
\hline $\mathrm{HC}$ & -0.64 & -0.31 & -1.90 & -1.11 & -0.80 & -2.25 & -0.73 & -0.48 & -1.67 \\
\hline
\end{tabular}

SGA: Small for gestational age, AGA: Appropriate for gestational age, HC: Head circumference 


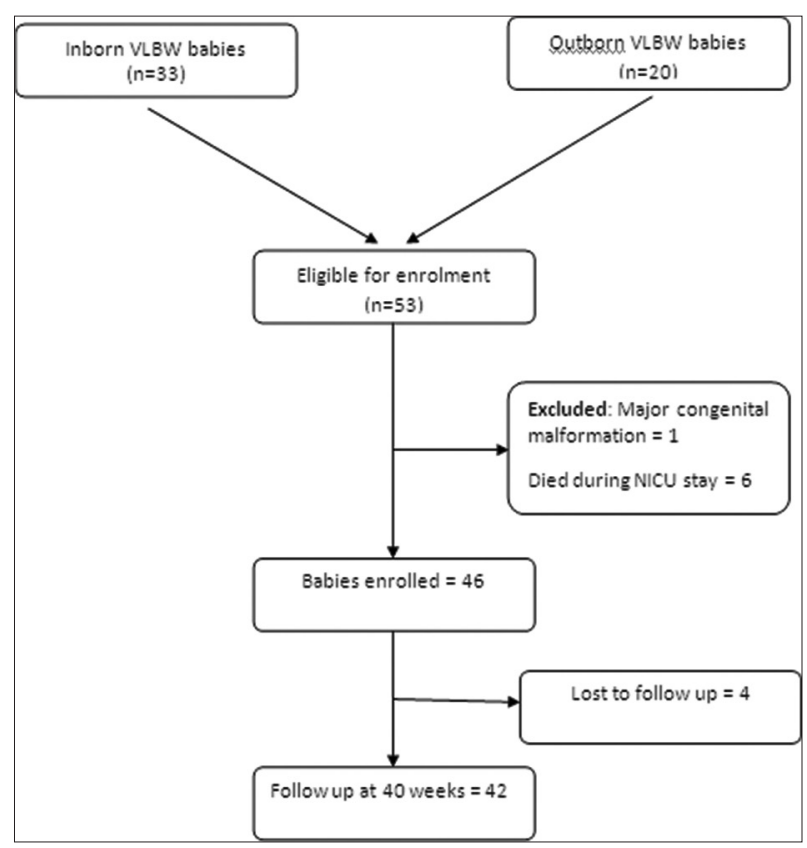

Figure 1: Flow diagram of patient enrollment and follow up

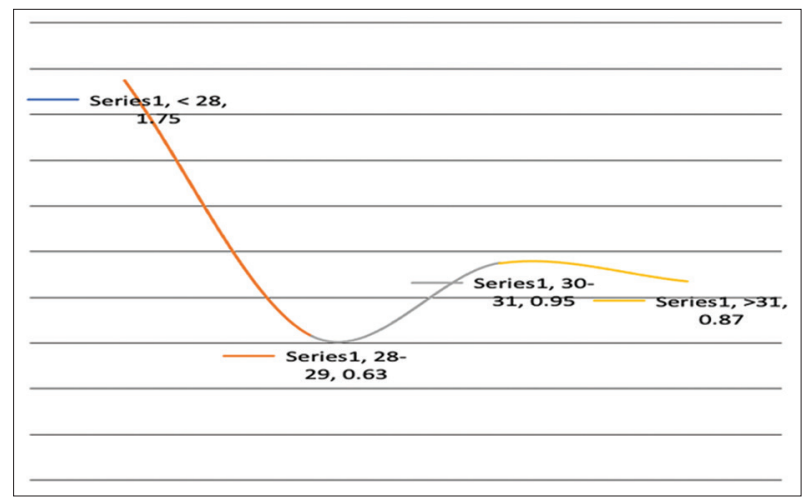

Figure 2: Change in Z-score from birth to corrected term gestation across birth weight

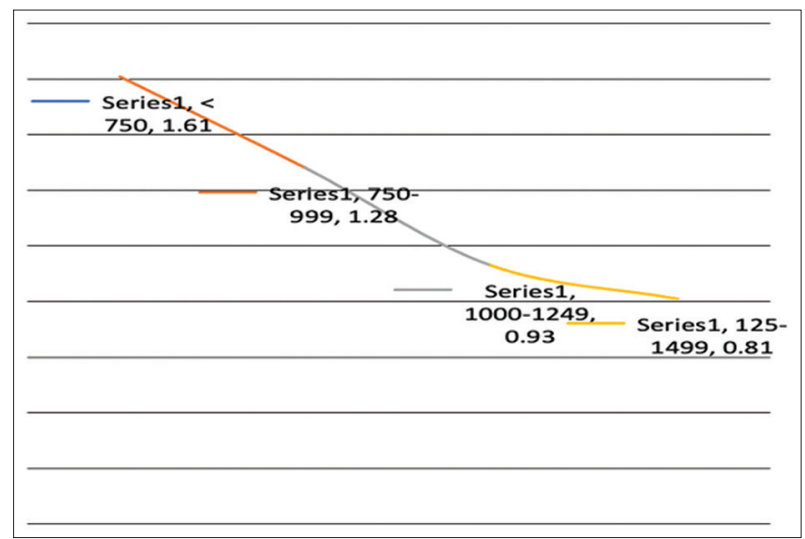

Figure 3: Change in Z-score from birth to corrected term gestation across gestational age category

Any anthropometric measurement that is chosen as an alternative to birth weight should be very sensitive so that the majority of LBW newborns would be identified for referral and extra care. At the same time, it has to be highly specific to prevent unnecessary referrals of normal weight babies to higher-level centers [21]. Several anthropometric measurements, including chest circumference, foot length, and mid-upper arm circumference, have been assessed as proxies for birth weight $[22,23]$. The head growth in the recovery phase is strongly associated with improved cognitive and motor outcomes; especially, in very preterm AGA infants. In contrast, SGAs showed different growth patterns, and the phase was not associated with neurodevelopmental outcomes A recent study by Kagithapu et al. [24], concluded that calf circumference as a single most useful anthropometric measure to predict LBW. Its sensitivity of $100 \%$ with a relatively higher specificity of $67.5 \%$ indicates its ability mainly to rule out LBW in a baby if calf circumference is $>10.5 \mathrm{~cm}$. Shlomai et al. [25] conducted a population-based study on VLBW infants born at 24-32 weeks of gestational age and who were discharged home at $\leq 40$ weeks CGA. In their study, the percentage of babies with severe growth failure decreased significantly from $11.5 \%$ in $1995-2000$ to $5.2 \%$ in $2006-2010$, and those with mild growth failure declined from $40.1 \%$ to $9.8 \%$ during these periods $(\mathrm{p}<0.001)$.

\section{Limitations}

Our study shows the trends in weight, length, and $\mathrm{HC}$ at birth, discharge, and 40 weeks post-menstrual age but has limitations, for example, it was a single-center study with a small sample size. Second, the observational design may be considered of low methodological quality. The accuracy of measurement lies in setting the standard limit (minimum limits) to identify the heights, length, and head circumstances. A high proportion (8.7\%) of the cases could not be followed up. A large-scale, multicenter study with detailed clinical data needs to be carried out in the future. A comparison of the growth with references from ethnically different populations would be more useful.

\section{CONCLUSIONS}

In our study, $21 \%$ of LBW infants were underweight at 40 weeks post-menstrual age. Both SGA and AGA infants exhibited a growth lag as indicated by a fall in $\mathrm{Z}$ scores for all three parameters from birth to discharge. We did not find any association between the infant diet and growth failure. Furthermore, the rapid progression of feeds did not have any significant adverse effects in our study population. A large multicentric randomized trial is warranted to compare the effect of exclusive aggressive enteral feeding with short-duration parenteral nutrition on long-term anthropometry and neurodevelopment outcome.

\section{REFERENCES}

1. Devaki G, Shobha R. Maternal anthropometry and low birth weight: A review. Biomed Pharmacol J 2018;11:815-20.

2. Cutland CL, Lackritz EM, Mallett-Moore T, Bardají A, Chandrasekaran R, Lahariya $\mathrm{C}$, et al. Low birth weight: Case definition and guidelines for data collection, analysis, and presentation of maternal immunization safety data. Vaccine 2017;35:6492-500.

3. Chaudhari S, Bhalerao MR, Chitale A, Pandit AN, Nene U. Pune low birth weight study-a six-year follow up. Indian Pediatr 1999;36:669-76.

4. Fenton TR. A new growth chart for preterm babies: Babson and Benda's 
chart updated with recent data and a new format. BMC Pediatr 2003;3:1.

5. Fenton TR, Elmrayed S, Alshaikh B. Nutrition, growth and long-term outcomes. World Rev Nutr Diet 2021;122:12-31.

6. UNICEF. The State of the World's Children 2009. Maternal and Newborn Health. New York, United States: UNICEF; 2008. Available from: https://www. unicef.org/media/84866/file/SOWC-2009.pdf. [Last accessed on 2021 Dec 25].

7. WHO, Global Nutrition Targets 2025: Low Birth Weight Policy Brief Geneva; 2014. Available from: https://www.apps.who.int/iris/bitstream/ handle/10665/149020/who_nmh_nhd_14.5_eng.pdf? sequence=2hyperlink; https://www.apps.who.int/iris/bitstream/handle/10665/149020/WHO_ $\mathrm{NMH}$ NHD_14.5_eng.pdf? sequence $=2 \&$ isAllowed $=y$. [Last accessed on 2021 Dec 25].

8. Mukhopadhyay K, Mahajan R, Louis D, Narang A. Longitudinal growth of very low birth weight neonates during first year of life and risk factors for malnutrition in a developing country. Acta Paediatr 2013;102:278-81.

9. Faye PM, Diagne-Gueye NR, Paraiso IL, Guèye M, Dieng YJ, Thiongane A, et al. Croissance ponderale postnatale des nouveau-ne's de faible poids de naissance au service de neonatologie du centre hospitalier national d'enfants Albert Royer: Incidence du retard de croissance extra-uterin. J Pediatr Pueric 2016;29:20-7.

10. Rochow N, Raja P, Liu K, Fenton T, Landau-Crangle E, Göttler S, et al. Physiological adjustment to postnatal growth trajectories in healthy preterm infants. Pediatr Res 2016;79:870-9.

11. Kim ES, Sohn JA, Lee EH, Choi EJ, Lee HJ, Lee JA, et al. Extra uterine growth restriction in very low birth weight infants. J Korean Soc Neonatol 2010;17:53-63.

12. Rover MM, Viera CS, Silveira RC, Guimarães AT, Grassiolli S. Risk factors associated with growth failure in the follow-up of very low birth weight newborns. J Pediatria 2016;92:307-13.

13. Chand S, Ahmed F, Shah MH, Leghari AL, Usman P, Advani R, et al. Frequency of early morbidities in low-birth-weight neonates at the Aga Khan University Hospital, Karachi. Cureus 2019;11:e6061.

14. Lee SM, Kim N, Namgung R. Prediction of postnatal growth failure among very low birth weight infants. Sci Rep 2018;8:1-8.

15. Chabra S. Small for gestational age and low birth weight: Distinct entities. Am J Gastroenterol 2018;113:441-2.

16. et al. Background rates of adverse pregnancy outcomes for assssing the safety of maternal vaccine trials in Sub-Saharan Africa. PLoS One 2012;7:e46638.

17. Saluja S, Modi M, Kaur A, Batra A, Soni A, Garg P, et al. Growth of very low birth-weight Indian infants during the hospital stay. Indian Pediatr 2010;47:851-6.

18. Sung IK, Vohr B, Oh W. Growth and neurodevelopment outcome of very low birth weight infants with intrauterine growth retardation: Comparison with control subjects matched by birth weight and gestational age. J Pediatr 1993;123:618-24.

19. Jaiswal A, Reddy A, Gaddam P, Murki S. Growth and nutritional status at corrected term gestational age in very low birth weight infants. Indian J Pediatr 2011;78:673-8.

20. Gianini NM, Vieira AA, Moreira ME. Evaluation of the nutritional status at 40 weeks corrected gestational age in a cohort of very low birth weight infants. J Pediatria 2005;81:34-40.

21. Otupiri E, Wobil P, Nguah SB, Hindin MJ. Anthropometric measurements: Options for identifying low birth weight newborns in Kumasi, Ghana. PLoS One 2014;9:e106712.

22. Ashish KC, Nelin V, Vitrakoti R, Aryal S, Målqvist M. Validation of the foot length measure as an alternative tool to identify low birth weight and preterm babies in a low-resource setting like Nepal: A cross-sectional study. BMC Pediatr 2015;15:43.

23. Thi HN, Khanh DK, Thu HL, Thomas EG, Lee KJ, Russell FM. Foot length, chest circumference, and mid-upper arm circumference are good predictors of low birth weight and prematurity in ethnic minority newborns in Vietnam: A hospital-based observational study. PLoS One 2015;10:e0142420.

24. Kagithapu S, Gudur V, Ravikumar C. Identification of low-birth-weight babies by birth weight-independent anthropometric measures. Indian J Child Health 2018;5:682-5.

25. Ofek Shlomai N, Reichman B, Lerner-Geva L, Boyko V, Bar-Oz B. Population-based study shows improved postnatal growth in preterm very-low-birth-weight infants between 1995 and 2010. Acta Paediatr 2014;103:498-503.

Funding: None; Conflicts of Interest: None Stated.

How to cite this article: Janjua D, Singh J, Agrawal A, Jadhav DV. Prospective observational study to assess the somatic growth in very low birth weight infants. Indian J Child Health. 2022; 9(1):6-10. 